\title{
IS CORTICAL SPOKE CATARACT DUE TO LENS FIBRE BREAKS? THE RELATIONSHIP BETWEEN FIBRE FOLDS, FIBRE BREAKS, WATERCLEFTS AND SPOKE CATARACT
}

\author{
NICHOLAS PHELPS BROWN ${ }^{1}$, MARTIN L. HARRIS ${ }^{1}$, G. ADRIEN SHUN-SHIN ${ }^{1}$, \\ GIJS F. J. M. VRENSEN ${ }^{2}$, BEN WILLEKENS ${ }^{2}$ and ANTHONY J. BRON ${ }^{1}$ \\ Oxford and Amsterdam
}

\begin{abstract}
SUMMARY
Fibre folds, previously called lamellar separation of the lens, have been found by electron microscopy to be associated with fibre breaks, which are seen in vivo as the circular shades of Obazawa. This led to the present study to determine the relationship between fibre folds, fibre breaks, waterclefts and spoke cataract. All lenses with fibre folds were found to have circular shades. A few instances of circular shades without fibre folds were found, suggesting that the fibre break may be the primary pathology. It was found that circular shades occurred in association with spoke cataract only when fibre folds were also present. Thus there is no essential causal relationship between fibre breaks and spoke cataract. The occurrence of waterclefts was unrelated to the presence of the other features. The lower nasal quadrant of the lens was the most common site for the four features. The depth of spoke cataracts was found to be unrelated to the age of the patient, which makes it unlikely that accommodational stress at the time of onset of presbyopia is causative.
\end{abstract}

In an earlier study ${ }^{1}$ we showed by electron microscopy that fibre folds, which had previously been considered by their slit lamp appearance to represent lamellar separation between the fibres of the lens, ${ }^{2.3}$ are associated with fibre breaks. The breaks are found in the near equatorial periphery of the lens (Fig. 1B,C). The counterpart of fibre breaks, as seen in the extracted lens (Fig. 1A) and in vivo at the slit lamp microscope (Fig. 2A, B), appears to be the near equatorial circumferentially running opacities, described by Obazawa $^{4}$ as circular shades. It seemed reasonable to suggest ${ }^{1}$ that the fibre breaks had a causal

From: 'Clinical Cataract Research Unit, Nuffield Laboratory of Ophthalmology, Oxford, UK; ${ }^{2}$ Department of Morphology, The Netherlands Ophthalmic Research Institute, Amsterdam, The Netherlands.

Correspondence to: Nicholas Phelps Brown, Clinical Cataract Research Unit, Nuffield Laboratory of Ophthalmology, Walton Street, Oxford OX2 6AW, UK.

Eye (1993) 7, 672-679 relationship with the fibre folds and that these breaks might be the primary pathology that gave rise to the fibre folds. To confirm this hypothesis it would be necessary to show a high correlation between the occurrence of fibre folds and of fibre breaks, which this study addresses. It also seemed reasonable to consider whether fibre breaks might be related to the development of cortical spoke cataract and to the development of waterclefts.

Fisher ${ }^{5}$ observed that the depth of cortical spoke cataract in the lens corresponded with the site of maximal fibre strain in accommodation and considered that the accommodational stress associated with presbyopia might damage the fibres and so be responsible for spoke cataract. The accommodational stress theory has also been supported by Pau. ${ }^{6}$ An alternative theory of fibre stress is that of Harding et $a l^{7}{ }^{7}$ in which the stress is thought to be incurred by the compaction of the cortical fibres towards the more resistant nucleus. These observations gave further encouragement to the idea that spoke cataract might result from fibre breaks.

\section{MATERIALS AND METHODS}

1. Any patient over the age of 50 who underwent mydriasis in our unit was studied for the presence of fibre folds and/or spoke cataract. In lenses showing either or both of these features the presence of circular shades and waterclefts was recorded. One hundred eyes in 100 patients were included. The eyes were examined with full mydriasis using two applications of cyclopentolate $1 \%$ and of phenylephrine $10 \%$.

The anterior cortex was studied at the slit lamp using focal illumination. A three-mirror lens examination was included to ensure that no peripherally situated circular shades were missed. In practice it was found that this examination was not essential since it was possible to observe all circular shades by asking the patient to direct the eye away from the primary position. Selected patients 

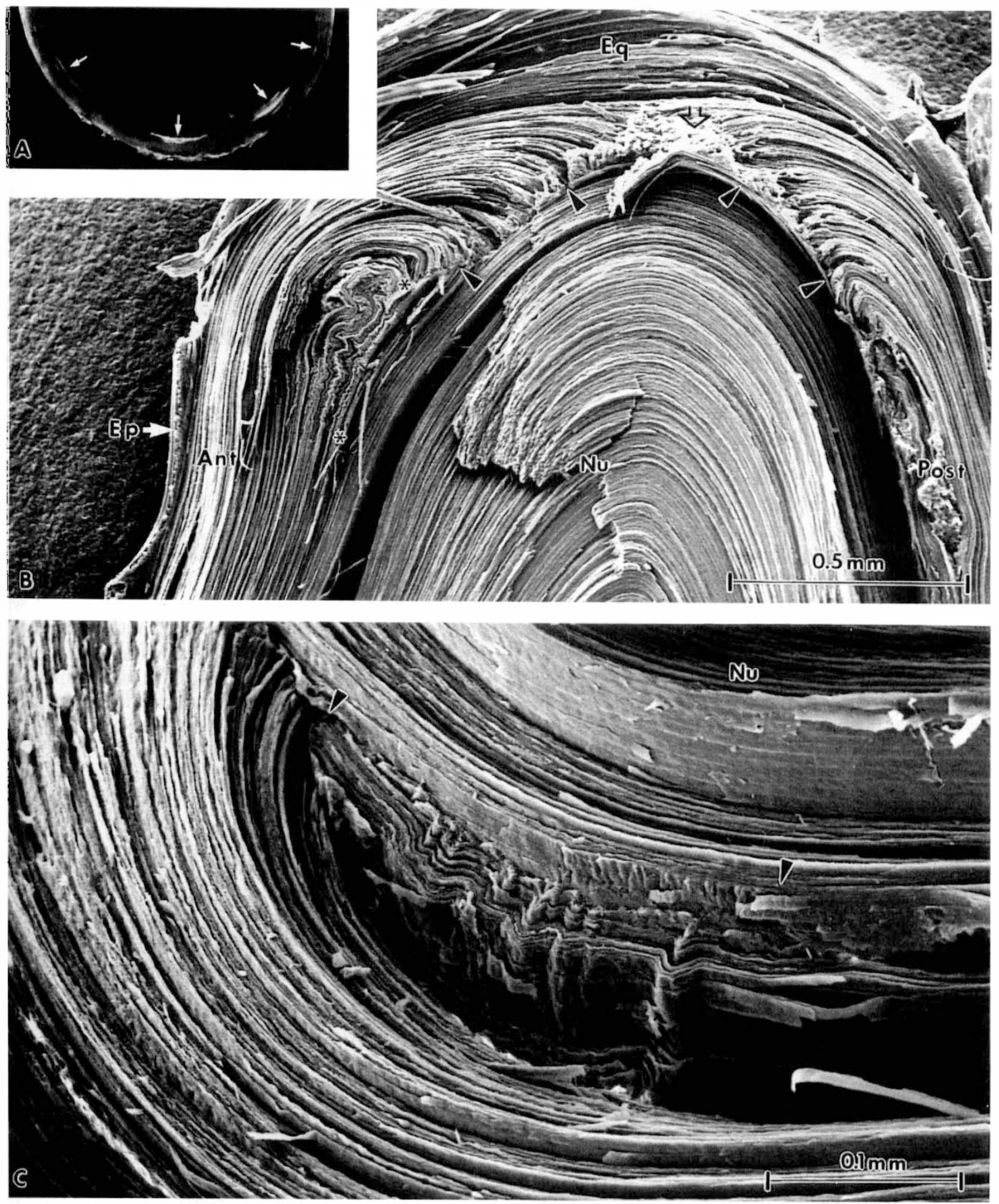

Fig. 1. Circular shades in the human lens. (A) Dark field micrograph showing the concentric nature of the opaque circular shades (arrows). (B) Survey scanning electron micrograph (SEM) of a lens with a circular shade showing the disturbed opaque region in the deep equatorial cortex (open arrow), the broken anterior and posterior fibres (between arrowheads) and the fibre folds in the deep anterior cortex (between asterisks). The superficial cortical fibres and the nuclear fibres are unaffected. Ep, epithelium; Ant, anterior cortex; Post, posterior cortex; Eq, equatorial cortex; Nu, nucleus. (C) Medium-power SEM of a region of fibre folds (between arrowheads). $\mathrm{Nu}$, nucleus. (For further details see Vrensen and Willekens ${ }^{13}$.) 


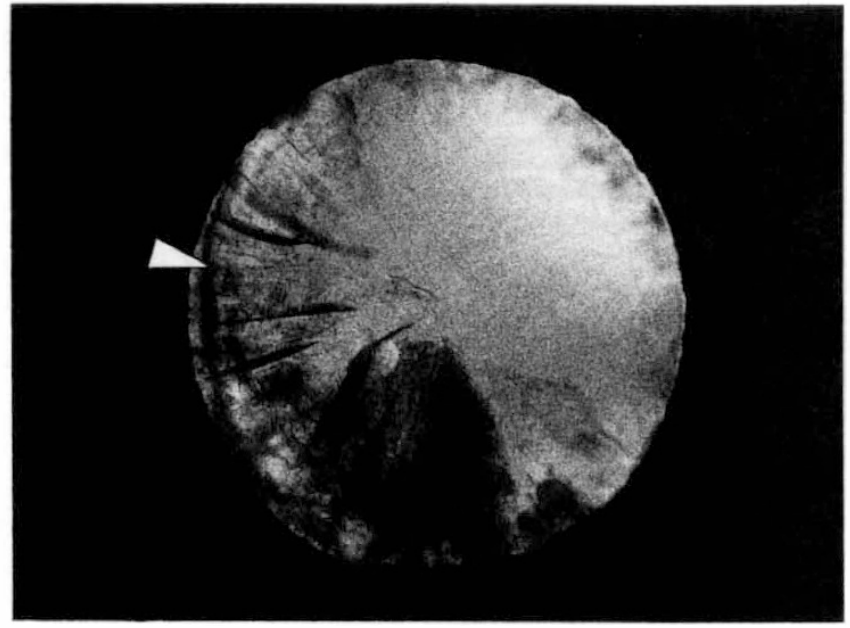

(A)

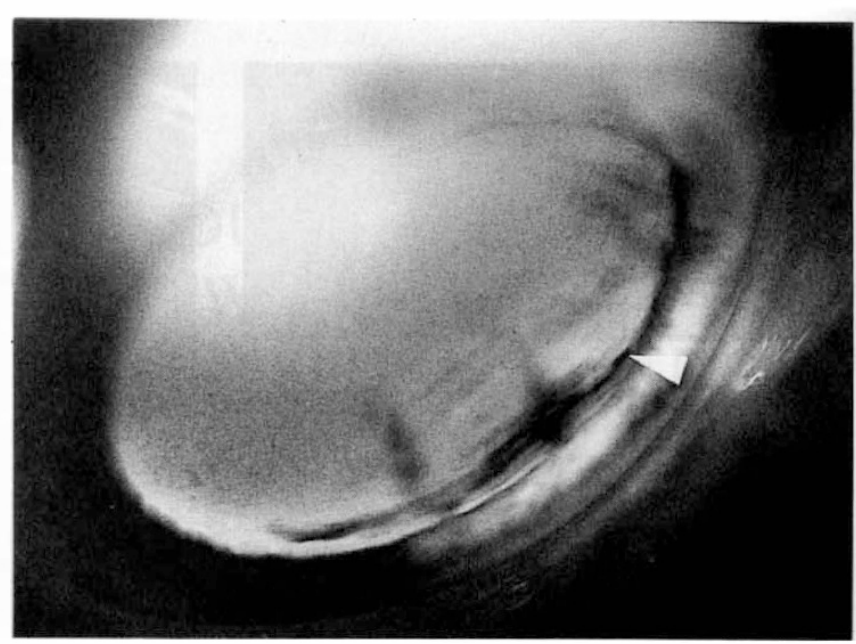

(B)

Fig. 2. (A) A circular shade (arrowhead) visible in the primary position in a lens with spoke cataract (Oxford retro-illumination camera). (B) A circular shade (arrowhead), not visible in the primary position, is seen in the right eye looking down and to the left (Oxford retro-illumination camera).

were photographed on the Oxford retro-illumination camera (Fig. 2A, B). ${ }^{8}$

The presence and site of each of the four studied features - spoke cataract, fibre folds, circular shades and water clefts - were recorded in the four quadrants of the anterior cortex of lens using the Oxford Clinical Cataract Classification and Grading System. ${ }^{9}$ The posterior cortex, in which these features also occur, but are observed with less accuracy, was not recorded.

2. Slit image photographs were made of 50 consecutive patients with cortical spoke cataract, Oxford grade 1 or $2,{ }^{9}$ taking part in a clinical trial. The Case 2000 CCD cataract recording camera and image analysis software were used. ${ }^{10,11}$ From these photographs the depth of the anterior cortical spoke opacity was measured from the lens surface. Forty-two eyes were measurable. A previous study ${ }^{12}$ showed that opacities that are subcapsular at their time of origin sink into the lens at a rate of $0.015 \mathrm{~mm}$ (uncorrected for corneal magnification) per year. This information was used to estimate the age of origin of the fibres involved in spoke cataract.

3. Surgically extracted lenses (Oxford) and lenses from donor eyes (Corneabank Amsterdam) exhibiting the features indicated have been studied with scanning and transmission electron microscopy using procedures detailed in the papers by Vrensen, ${ }^{13-15}$ Van Marle ${ }^{16}$ and Willekens. ${ }^{17}$ This material has been used to illustrate the structural aspects of the clinical features studied in this paper.

Table I. Relationship between features

\begin{tabular}{lll}
\hline & RS & $P$ \\
\hline Circular shades/spokes & 0.28 & 0.005 \\
Circular shades/folds & 0.81 & 0.001 \\
Circular shades/clefts & 0.06 & 0.57 \\
Spokes/clefts & 0.12 & 0.22 \\
Spokes/folds & 0.26 & 0.009 \\
Clefts/folds & 0.14 & 0.16 \\
\hline
\end{tabular}

RS, Spearman rank correlation corrected for ties.

\section{RESULTS}

The relationship between the four separate features is shown in Table I. It is seen that there is a very strong correlation between the presence of fibre folds and circular shades. Indeed circular shades were found in all eyes with fibre folds and only a few instances of circular shades were found in which fibre folds were not present. The presence of circular shades might appear to be related to spoke cataract (Table I), but spokes are found in the absence of circular shades and are found in association with circular shades only when fibre folds are also present.

All four features occur with greater frequency in the lower part of the lens, particularly in the lower nasal quadrant (Fig. 3).

The depth of cortical spoke cataracts measured from the surface was found to be $0.02-0.78 \mathrm{~mm}$ with a mean of $0.57 \mathrm{~mm}$. There was no significant correlation between the age of the patient and the depth of the opacity (Fig. 4; $r=0.13, p=0.40)$. The rate at which opacities sink into the lens ${ }^{12}$ of $0.015 \mathrm{~mm}$ per year was used to calculate the

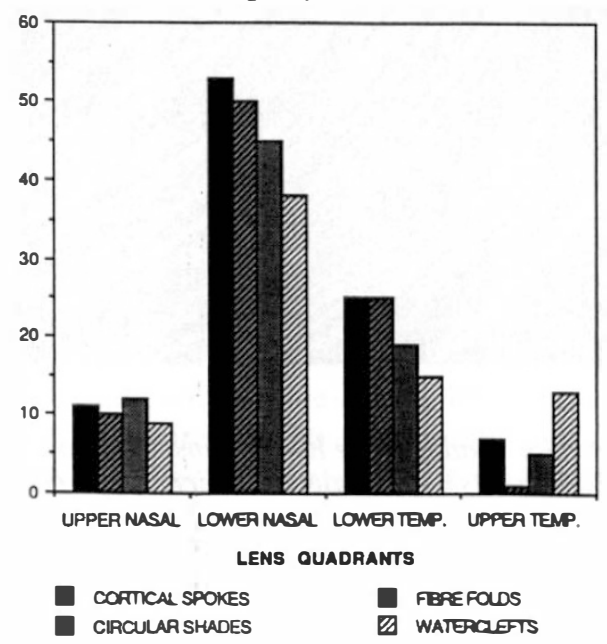

Fig. 3. Distribution of cortical features by lens quadrant. 


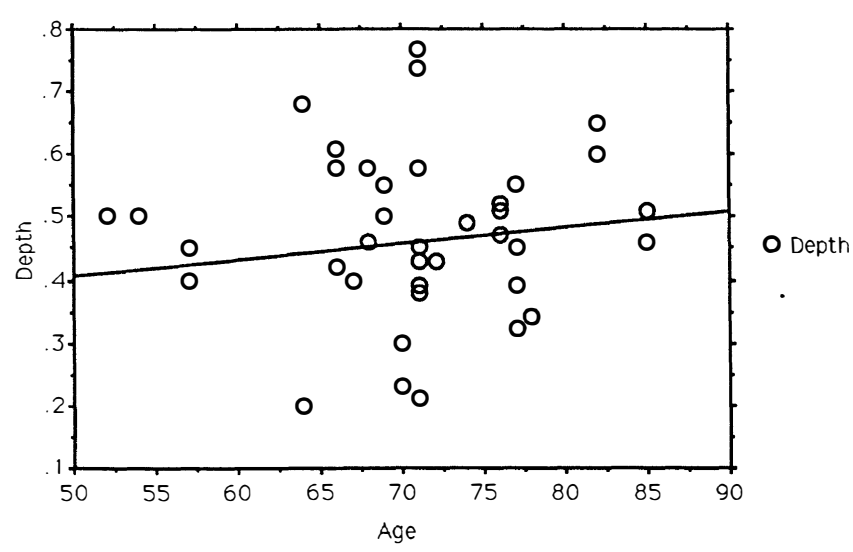

Fig. 4. The relationship between the depth of spoke opacities and the age of the patient. The equation for the regression line is $\mathrm{y}=0.002 \mathrm{x}+0.283\left(\mathrm{r}^{2}=0.018\right)$.

age at which the opacity would have been initiated. The age range was found to be $17-57$ years with a mean of 38.1 years. This calculation makes the assumption that a fibre affected by spoke cataract was subcapsular at the time the disorder was initiated.

\section{DISCUSSION}

Lens opacities arise as a result of derangement of the lens fibre cell architecture or loss of transparency of the lens fibre contents. The form of lens opacities is determined by the structure of the lens ${ }^{18}$ and there are a limited number of ways in which an opacity may form. There are two basic categories: fibre-based opacities and non-fibre-based opacities. In the former, the shape of the opacity is determined by the lens fibre architecture and in the latter it is not. The cortical spoke opacity is an example of a fibrebased opacity and follows the course of the lens fibres from the periphery as far, eventually, as the fibre terminations at the lens suture. The histological appearance of this type of opacity (Fig. 5) shows that there is disruption of fibre membranes as well as disturbance of the internal substance of the fibre. This is in distinction to age-related nuclear cataract in which the fibre architecture is undisturbed and the opacity is accounted for by increased protein molecular size in the cytoplasm causing scattering.

Cortical spoke cataracts are seen to grow in a centripetal direction from an origin near the equatorial periphery. The growth is shown by ultrastructural inspection to lie within and to follow the course of a limited cohort of fibres both anteriorly and posteriorly without interruption in the equatorial region. ${ }^{13}$ Within the cohort of affected fibres the fibrelimiting membranes are disrupted and the cytoplasm changed into a mass of globular elements (Fig. 5B, C and D). Clinical observation also shows that the spokes expand along the circumference. Thus their mode of growth indicates that the opacification passes along individual fibres and also spreads to the adjacent fibres. The rate of spread is variable and periods occur in which opacity growth appears arrested. Each individual fibre represents a single tube of protoplasm bordered by plasma membranes which extensively interdigitate with adjacent fibres by edge protrusions and by grooves and ridges. ${ }^{15}$ They are linked functionally to one another by gap junctions. Thus it is surprising that rapid spread of opacity does not take place from its site of origin into adjacent fibres. The proposed hypothesis ${ }^{18}$ is that an annealing process exists to seal off the defective part of a fibre from the normal part and that a gap junctional gating mechanism exists to separate a damaged fibre from normal adjacent fibres. The existence of annealing membranes across damaged fibres and of altered junctional complexes between fibres has been demonstrated. ${ }^{13,14}$ In addition it has been shown ${ }^{16}$ that in the normal human deep cortex the fibre-limiting membranes have a deviant architecture with a paucity of intramembrane particles and 'degenerative' gap junctions. This is likely to mean that the export of factors initiating fibre breakdown is limited. It was also shown ${ }^{14}$ that spoke opacities are bordered by membranes covered with numerous so-called square arrays (Fig. 5E). These represent the morphological counterpart of the uncoupling of neighbouring cells and of uncoupling, or annealing, within an individual fibre.

A break in a lens fibre caused by trauma may initiate a cortical opacity, but the form of the typical concussion cataract is a radiating petal arrangement emanating from the central sutures and it seems likely that a breaking apart of the fibre tips at the suture is the cause. A peripheral fibre break might cause spoke cataract beginning in the periphery, but the type of peripheral fibre breaks that appear responsible for fibre folds are not directly associated with spoke cataract and therefore not the essential cause of spoke cataract.

Spoke cataracts are initially observed at a variable depth in the cortex (cortical levels $\mathrm{C} 2$ and $\mathrm{C} 3$, as defined in the Oxford Cataract Classification and Grading System ${ }^{9}$ ). The fibres in these layers were once superficial since new fibres are continually being formed at the surface and then compact into the lens with time. ${ }^{12}$ It has been suggested ${ }^{17}$ that the process initiating the opacity may have begun at the time when the affected fibres were superficial, but did not give rise to any clinically identifiable disorder at the time. Alternatively the initiation of spoke cataract may have begun close to the time of cataract formation in the older fibre at the depth where the opacity is first observed. The mechanical stresses that could cause fibre damage are accommodation affecting the fibre when superficial ${ }^{5}$ and compaction towards the resistant nucleus ${ }^{7}$ affecting the fibre when deep. Fisher ${ }^{20}$ was able to induce superficial opacities in vitro by the mechanical force of spinning the lens. The present study indicates a possible time of origin for spoke cataract at an average age of 38 , which might correspond to a time of accommodational stress as suggested by Fisher. However, the spread of the age of origin is 17-57 years and no correlation has been found between the depth of the opacity and the age of the patient at the time of observation. Thus no particular age of onset is indicated and it seems more probable that the process of spoke cataract formation is initiated at the depth at which it is found, rather than at a previous time when the affected fibres were superficial. The depth of initiation of spoke 

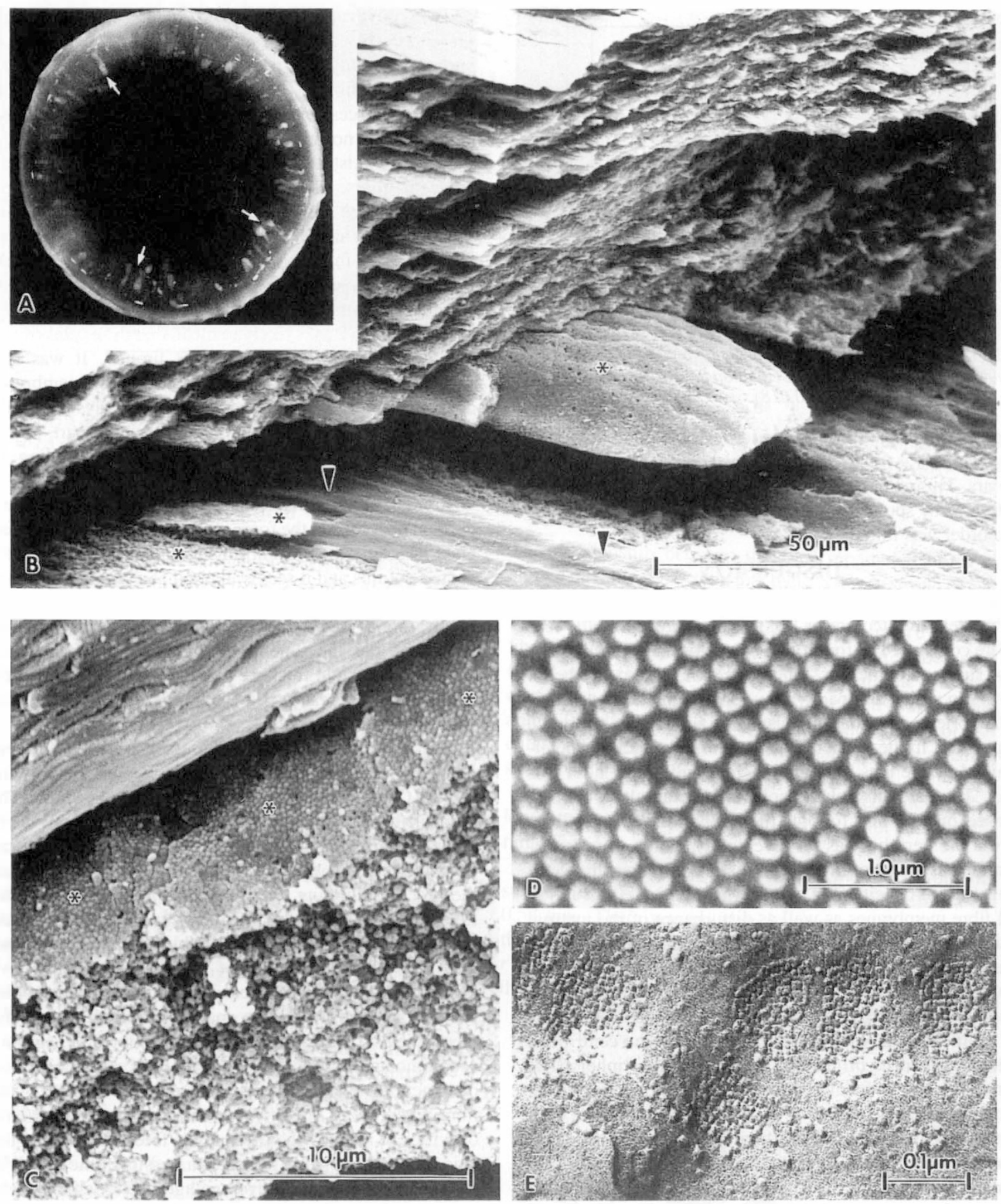

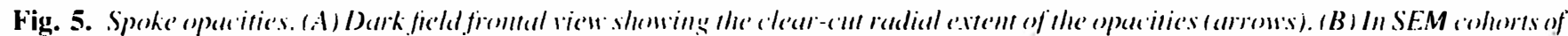

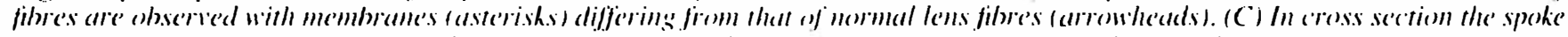

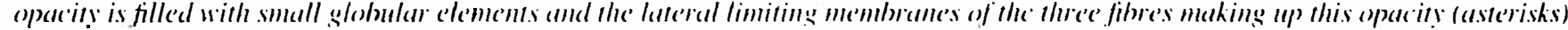

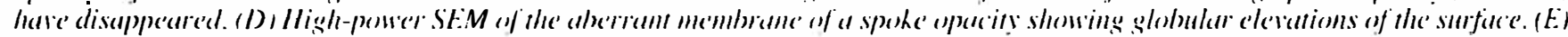

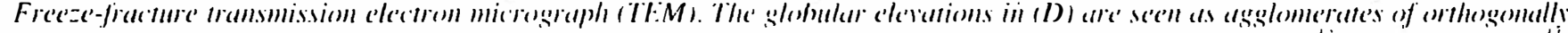

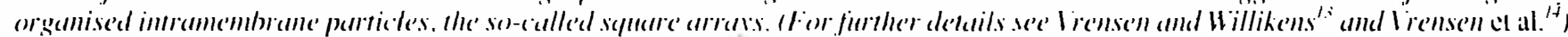

cataract is thus at any depth in the lens contex with the exception of the most superficial cortex.

Biochemical cataractogenic factors. such as lipid per- oxidation affecting the lens fibre membranes. cannot be excluded and at present must be regarded as an at least equally probable cause of opacity as the stress theories. 

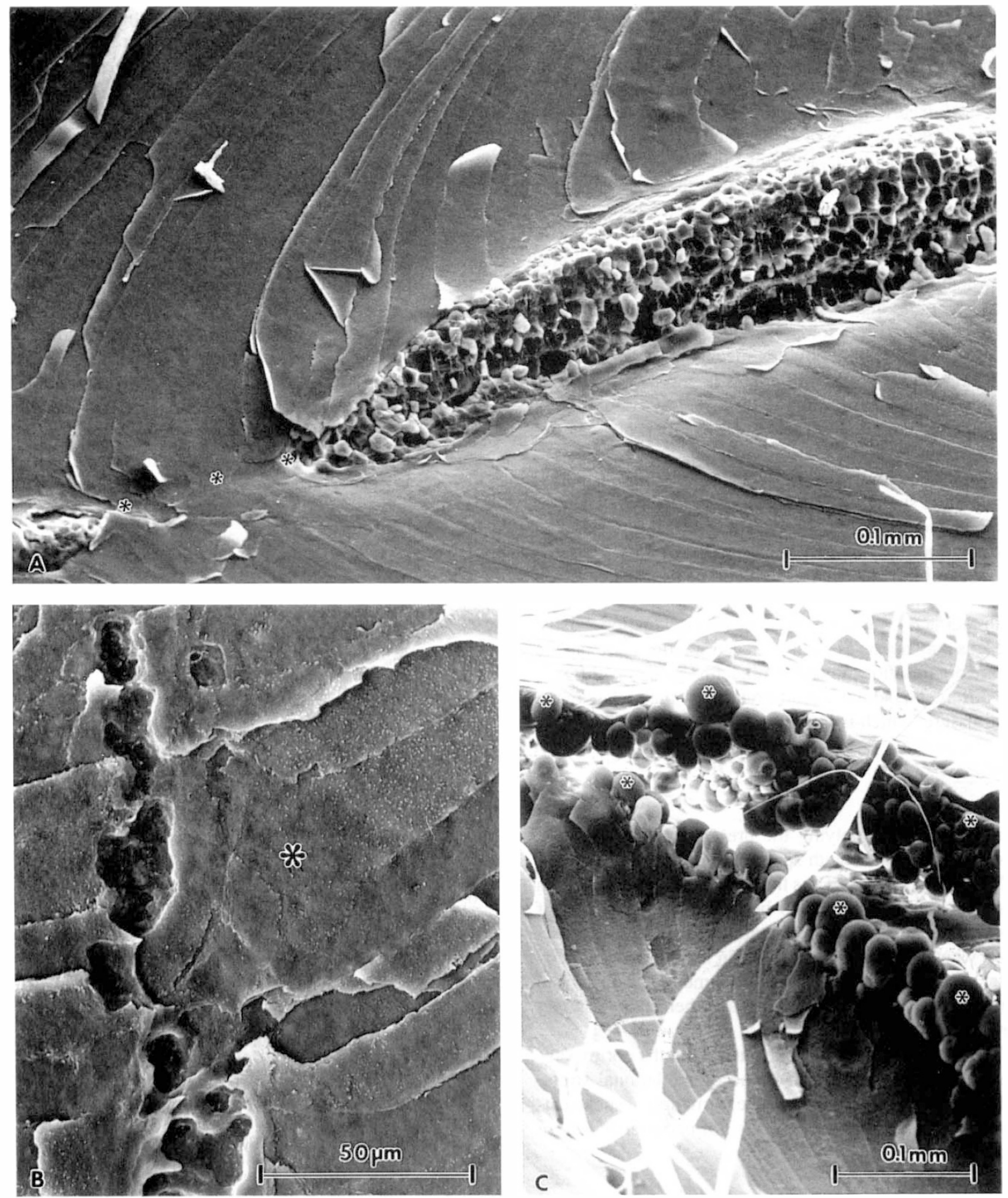

Fig. 6. (A) Survey SEM of a spindle-shaped expansion of the suture line (asterisks) filled with globular elements and surrounded by normal lens fibres. (B) Initial stage of watercleft formation in a lens suture. The interdigitating fibres (asterisks) have partly lost contact. (C) View of a watercleft clearly showing the globular elements (asterisks) originating from the separated fibres. (For further details see Shun-Shin et al. ${ }^{2 l}$ )

since the present study fails to link spoke cataract with fibre breaks, or with accommodational stress. However, mechanical damage to the fibre does not have to be in the form of a fibre break and may have another as yet unrecognised form.

Waterclefts are optically clear features running in the 
suture line and not likely to be confused with spoke cataract. Waterclefts are similarly radial and at the same location. They are made up of vacuolar structures the histology of which is known. ${ }^{21}$ It is not surprising to find that the occurrence of waterclefts is not significantly related to the presence of spoke cataract, circular shades, or fibre folds. The primary defect in watercleft formation is now considered to be separation of the fibre tips at the sutures (Fig. 6) ${ }^{21}$ from which the waterclefts spread.

It is curious that the three separate lens pathologies of spoke cataract, waterclefts and fibre folds are each most prevalent in the lower part of the lens and particularly in the lower nasal quadrant. This observation is not new and was made for fibre folds (lamellären Zerkluftung) by Schild $^{22}$ in 1921. The obvious mechanical candidate for affecting the lower part of the lens is gravity, but there is no convincing explanation as to how gravity might act. Gravity might act on high molecular weight protein aggregates within the fibre protoplasm causing the aggregates to descend to the lower part of the fibre. Each fibre is a long tube so that such movement is possible. However, aggregates in the upper fibres would be expected to descend towards the anterior and posterior lens poles. It is the lower part of the lens that is likely to be the most affected by solar radiation, which is epidemiologically associated with cataract, ${ }^{23,24}$ and this might be the explanation. Lastly, the lens may not be as symmetrical as it appears to be; the suture organisation may determine this ${ }^{25}$ and may differ in the different quadrants, or an asymmetry may relate to the fetal fissure, which is lower nasal.

\section{CONCLUSION}

\section{Spoke Cataract}

Circular shades, implying the presence of fibre breaks, occur in association with spoke cataract only when fibre folds are also present. Thus there does not appear to be an essential causal relationship between the occurrence of fibre breaks and the development of spoke cataract. However, when spoke cataract is seen in association with circular shades, the sequence of development may have been fibre breaks leading to fibre folds and then spoke cataract developing within these fibres.

The variable depth of spoke cataract in the cortex suggests that it is not initiated by accommodational stress. Whatever the primary defect in the formation of spoke cataract may be, it appears that it is not necessarily a fibre break.

\section{Waterclefts}

The occurrence of waterclefts is not causally related to the presence of spoke cataract, circular shades or fibre folds. The earliest demonstrable defect in watercleft formation appears to be separation of the fibre tips at the sutures. ${ }^{21}$

\section{Fibre Folds (Lamellar Separation)}

Lenses with fibre folds have circular shades, which have been shown to be fibre breaks. A few instances of circular shades without fibre folds occur, suggesting that the fibre folds are caused by formation of peripheral fibre breaks, but that an interval may exist in time between the circular shade presenting and the folding of the fibres.

The site of each of the four studied feature - spoke cataract, fibre folds, circular shades and waterclefts - was recorded in four quadrants of the lens. The features were distributed in a similar manner, with the lower nasal quadrant being the most affected, followed by the lower temporal and then by the upper quadrants. Apart from the tendency to occur in the same part of the ageing lens, the occurrence of spoke cataract, fibre folds and waterclefts appears to be otherwise unrelated. The fact that the lower part of the lens is affected more often may be due to an undefined gravitational effect, to solar radiation, or to asymmetry of the lens suture system.

This research project was sponsored at Oxford by the Violet M. Richards Charity.

Key words: Cataract, Lens fibre breaks, Lens fibre folds, Lens waterclefts.

\section{REFERENCES}

1. Brown NAP, Vrensen G, Shun-Shin GA, Willekens B. Lamellar separation in the lens: the case for fibre folds. Eye 1989;3:597-605.

2. Vogt A. Lehrbuch und Atlas der Spaltllampenmikroscopie des lebenden Auges. Vol. 2. Berlin: Springer, 1931:485.

3. Berliner ML. Biomicroscopy of the eye. Vol. 2. New York: Hoeber, 1949:1115.

4. Obazawa H, Fujiwara T, Kawara T. The maturing process of the senile cataractous lens. In: Henkind P, editor. Acta XXIV International Congress of Ophthalmology. American Academy of Ophthalmology. Philadelphia: JB Lippincott, 1983.

5. Fisher RF. Senile cataract: a comparative study between lens fibre stress and cuneiform opacity formation. Trans Ophthalmol Soc UK 1970;90:93-109.

6. Pau H. Clinical and biochemical aspects of different types of senile cataract. Lens Res 1986;3:265-70.

7. Harding CV, Susan SR, Lo W-K, Bobrowski WF, Maisel H, Chylack LT Jr. The structure of the human cataractous lens. In: Maisel $\mathrm{H}$, editor. The ocular lens: structure, function and pathology. New York: Marcel Dekker, 1985:chap 10.

8. Brown NAP. The Oxford retro-illumination cataract recording camera: a new instrument. J Audiovis Media in Med 1988;11:58-60.

9. Sparrow JM, Bron AJ, Brown NAP, Ayliffe W, Hill AR. The Oxford clinical cataract classification and grading system. Int Ophthalmol 1986;9:207-25.

10. Sparrow JM, Brown NAP, Shun-Shin GA, Bron AJ. The Oxford modular cataract image analysis system. Eye 1990;4:638-48.

11. Harris ML, Smith GTH, Brown NAP. Inter- and intra-observer reproducibility of the new Oxford CCD Scheimpflug camera. Eye 1991;5:487-90.

12. Brown N. Dating the onset of cataract. Trans Ophthalmol Soc UK 1976;96:18-23.

13. Vrensen G, Willekens B. Biomicroscopy and scanning electron microscopy of early opacities in the ageing human lens. Invest Ophthalmol Vis Sci 1990;31:1582-91.

14. Vrensen G, Van Marle J, Willekens B. Square arrays in early cortical lens opacities. Invest Ophthalmol Vis Sci 1990;31:2476-81. 
15. Vrensen G, Kappelhof J, Willekens B. Morphology of ageing human lens. Lens Eye Toxicity Res 1990;7:1-30.

16. Van Marle J, Vrensen G, Van Veen H. Maturing human eye lens fibre membranes and filipin cytochemistry. In Vrensen GF, Clauwaert J, editors. Topics in ageing research in Europe 15. Eye lens membranes and ageing. EURAGE 1992:261-71.

17. Willekens B, Kappelhof J, Vrensen G. Morphology of the aging human lens. Lens Res 1987;4:207-30.

18. Bron AJ, Brown NAP. Lens structure and forms of cataract. In Duncan G, editor. The lens: transparency and cataract. EURAGE 1986:3-11.

19. Costello MJ, Oliver TN, Cobo LM. Cellular architecture in age-related human nuclear cataracts. Invest Ophthalmol Vis Sci 1992;33:3209-27.

20. Fisher RF. Human lens fibre transparency and mechanical stress. Exp Eye Res 1973;16:41-9.
21. Shun-Shin GA, Vrensen G, Brown NP, Willekens B, Bron AJ, McDonald B. Does the pathogenesis of waterclefts reside in the lens fibre membrane? In: Vrensen GF, Clauwaert J, editors. Topics in ageing research in Europe 15. Eye lens membranes and ageing. EURAGE 1992:261-71.

22. Schild $H$. Untersuchungen über die Haufigkeit der lamellären Zerkluftung, ihre Lage und Verlaufsrichtung in der vorderen und hinteren Linsenrinde: an 218 Augen sonst gesunder Personen. Arch Ophthalmol 1921;107:49-50.

23. Weale RA. Senile cataract: the case against light. Ophthalmology 1983;90:420-3.

24. Taylor HR, West SK, Rosenthal FS, et al. Effect of ultraviolet radiation on cataract formation. $N$ Engl $J$ Med 1988;319:1429-33.

25. Kuszack JR, Sivak JG, Weerheim JA. Lens optical quality is a direct function of lens sutural architecture. Invest Ophthalmol Vis Sci 1991;32:2119-29. 